\title{
Ecological culture of students in the trends of the Concept of sustainable development
}

\author{
Yulia Grishaeva ${ }^{1, *}$, Alexander Gagarin ${ }^{2}$, Iosif Spirin $^{3}$, Zinaida Tkacheva ${ }^{1}$, Natalia \\ Evstafieva $^{1}$, and Oleg Napolov ${ }^{4}$ \\ ${ }^{1}$ Moscow Region State University, Department of Physical Geography, Nature Management and \\ Methods of Teaching Geography, 141014, 24, Very Voloshinoy st., Mytishchi city, Moscow Region, \\ Russia \\ ${ }^{2}$ Russian Presidential Academy of National Economy and Public Administration (RANEPA), Institute \\ of Social Sciences, Faculty of Psychology, 119571, 84, Vernadskogo prospect, Moscow, Russia \\ ${ }^{3}$ JSC Scientific \& Research Institute of Motor Transport, 125480, 24, Geroyev Panfilovtsev st., \\ Moscow, Russia \\ ${ }^{4}$ Moscow State University of Geodesy and Cartography (MIIGAiK), Department of Space \\ Monitoring and Ecology, 105064, MIIGAiK, 4, Gorokhovsky pereulok, Moscow, Russia
}

\begin{abstract}
The concept of sustainable development (SD) is used by the international community to address the complex interconnected social, environmental and economic challenges of modern society. Solving SD tasks depends on the quality of training of professionals who are currently receiving vocational education. One of the areas of SD is the participation of specialists from various fields of activity in solving environmental problems. Therefore, the purpose of this article is to consider the ecological culture of students in the trends of the concept of sustainable development. The trends of the concept of SD and professional education, models of pedagogical interaction, aspects of the formation of the environmental culture of students, features of the modern state and trends of eco-cultural development of students, connection of this level with the achievement of SD goals are shown. The article provides experimental results of the study of attitude of Russian students to various aspects of environmental conservation. These results demonstrate the possibility and need to improve the environmental culture of students. The use of the article materials by educators will allow them to more effectively and purposefully shape the students' environmental competences.
\end{abstract}

\section{Introduction}

The depressing impact of anthropogenic activities on the environment was predicted more than a century ago by Eduard Louis Emmanuel Julien Le Roy (1870-1954), Pierre Teilhard de Chardin (1881-1955) who developed the noosphere doctrine. Along with the growing environmental problems contradictions in economic and social relations have now become more acute which allows us to speak of a systemic crisis of civilization. There was a need for

${ }^{*}$ Corresponding author: j.m.g@mail.ru 
a comprehensive solution to these interrelated problems. The concept of sustainable development (SD) is recognized by the international community as an imperative of balanced development at the international and national levels. It is aimed at a harmonized solution of a complex of social, environmental and economic problems and contradictions in the interests of present and future generations. The conceptual framework and goals of the SD are approved by UN documents [1, 2, 3].

The implementation of the concept of SD requires the efforts of all of humanity, but the crucial contribution to successful sustainable development is called upon to make the cognitariat. The cognitariat is an educated part of society. Currently, the knowledge economy in developed countries prevails over the traditional economy of machine production, and creates the largest share of GDP [4]. Education, along with science, has become the leading productive force of society. Therefore, the improvement and development of education is the main vector of implementing the concept of sustainable development.

Since the environmental component is one of the main factors of SD, environmental knowledge should be available to specialists working in various fields of activity. Our previous studies have shown that environmental knowledge should be available to educated people of all ages, without excluding professional profiles. Environmental specialists use this knowledge as a basis for their professional skills. Other representatives of the cognitive community should use environmental knowledge as a natural «background» when solving problems in their field of activity. The presence of ecological knowledge and the ability to use it in practice have a direct impact on the ecological-oriented worldview of an individual, and indicate the level of his ecological culture. Ecological culture is formed in the human mind throughout life. The greatest contribution to the eco-cultural development of the representatives of the cognitariat is made by the stage of training in vocational education institutions. The study of the state and formation of the ecological culture of students is aimed at achieving the SD goals.

Hence, the purpose of this article is to study the ecological culture of students in the trends of the concept of sustainable development.

\section{Methods and materials}

The methodological base of the research includes general scientific methods in combination with the methods of special scientific areas: ecology, sustainable development, pedagogy, modeling of the eco-cultural level of students' personality, netnography, statistics. The information basis of the study was the results of netnographic studies of the attitudes of students of Russian universities to the environment, the analysis of publications on the article considered the problem, the study authors' ecological culture of students in the conditions of digitalization of the environmental education.

\section{The trends of the concept of SD and professional education}

General conceptual didactic model of the ecological development of the person in the multicultural digital educational environment of the university

When solving priority tasks, a conceptual didactic model of environmental development of the student's personality was developed, including:

a) the interaction of man and his environment in evolutionary and historical development;

b) the correspondence of the mind with the physical body and the environment, as part of the cognitive system;

c) interconnected information and environmental development of the person in the online environment; 
d) individual-typological differences of personality in connection with the peculiarities of human behavior in online and offline communication interactions;

e) amplification of the meanings of the teaching in the online environment, which leads to the creation of conditions for the free socio-cultural development of the person [5].

The didactic component of the model is formed based on the following:

a) the goal and result of the ecological development of the students ' personality in a multicultural digital educational environment is an ecological-oriented self-awareness, the key characteristic of which is the pro-ecological behavior of the individual in various social and life situations [6];

b) the didactic principles underlying the design of the ecological development of the person in a multicultural digital educational environment are divided into: general

didactic (visibility, independence, accessibility, etc.);

psychodidactic (reflexivity, activity, variability, complementarity of the digital educational environment);

special, related to the digitalization of the educational environment (information-environment, information-communication, information-personal);

special issues related to the multiculturalism of the digital educational environment (taking into account the established traditions and norms of behavior of ethnic and social groups to which students belong; the use of effective cross-cultural online communication technologies; the use of effective cross-cultural communication technologies in the social space of equal cultures and subcultures) [7];

c) the content of training aimed at the ecological development of the students' personality is determined by the universal digital content of the multicultural digital educational environment, which is didactically embodied in the knowledge, skills, experience of creativity and emotional-value attitude to reality with the support of the teacher $[5,8]$;

d) technologies and the process of student inclusion are aimed at the ecological development of the individual in a multicultural digital educational environment;

e) position on the role of teacher-student interactive online collaboration reflects the diversity of subjects' multicultural digital educational environment, their interaction and autonomy, the specificity of the target orientation.

A system for designing specific didactic models of multicultural digital educational environments based on a higher educational institution.

The design of specific didactic models of multicultural digital educational environments of the university is implemented through: the

its structural components (design, constructive, gnostic, organizational, communicative);

general procedure for organizing the gradual inclusion of students in training in the conditions of the model of a multicultural digital educational environment;

didactic provision of teacher training for students in a multicultural digital educational environment.

The process of students' inclusion in learning in the conditions of each of the developed models of multicultural digital educational environment is divided into five stages (Fig. 1) and its didactic content is defined as follows:

purposeful organization of educational and communication online and offline interactions between students and teachers;

these interactions are mediated by digital technologies, implemented through didactic support;

the goal of didactic support at the first stage is to acquire students' skills of teamwork in a multicultural digital educational environment;

the goal of didactic support in the future is to master and develop independent learning activities in a multicultural digital educational environment. 


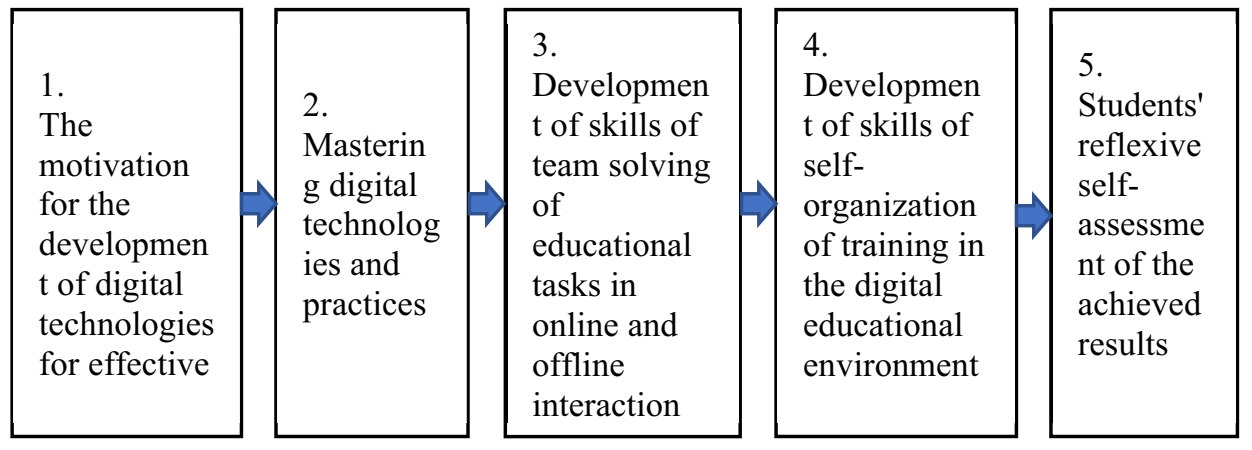

Fig.1. Five stages of students' inclusion in the training according to the developed models

\section{Empirical results of studying students' attitudes to environmental problems}

Ecological self-awareness manifests itself in the context of the anthropocentric and ecocentric behavior of individuals. A statistical study of the students' attitude to environmental problems allowed Kudriavtseva V.I. at al. to form a list of 760 factors that students consider necessary to pay attention to. The students ' attitude to the preservation of the environment was distributed according to the share of interested persons as follows: pollution problems $-37.6 \%$, the need for resource conservation in everyday life and at work $-25.7 \%$, health preservation $-9 \%$, increasing the environmental activity of the population $-6.2 \%$, caring for fauna and flora $-5.5 \%$, raising awareness and environmental literacy $3.2 \%[9]$.

The study of the works of various authors has shown that experimental studies carried out in different countries indicate that environmental education forms a deep understanding of the problems of environmental conservation, economical consumption of natural resources, and the need for sustainable development. These eco-cultural attitudes of students are manifested both in everyday life and in the sphere of their professional activity $[10,11]$.

In 2020-2001, within the framework of the project «Multicultural design of the ecological development of the personality in digital education», the authors conducted an experimental study of the attitude of students of Russian universities and colleges to environmental problems in the context of the implementation of the concept of sustainable development. The study was conducted using netnography methods.

The sample size was 9395 students (university students $40 \%$, secondary school students $60 \%$ ). The composition of students by gender roughly corresponds to the demographic statistics of the population (women 4868 people, men 4527 people). The majority of students (7774 people) are aged 17-20 years. The composition of the contingent of students in the professional profile is adequate to the structure of graduates of educational institutions: technical and technological - 48\%; humanitarian - 39\%; natural science - $9 \%$, creative - 4\%. The representativeness of the sample was ensured by using the methods of mathematical statistics under the following conditions: confidence probability 0.95 , acceptable error $5 \%$. Students' answers to pre-developed questions from 11 subjects of the Russian Federation were received.

The share structure of students' responses to questions about their personal activity and interest in solving environmental problems is shown in Fig. 2 and Fig. 3. 


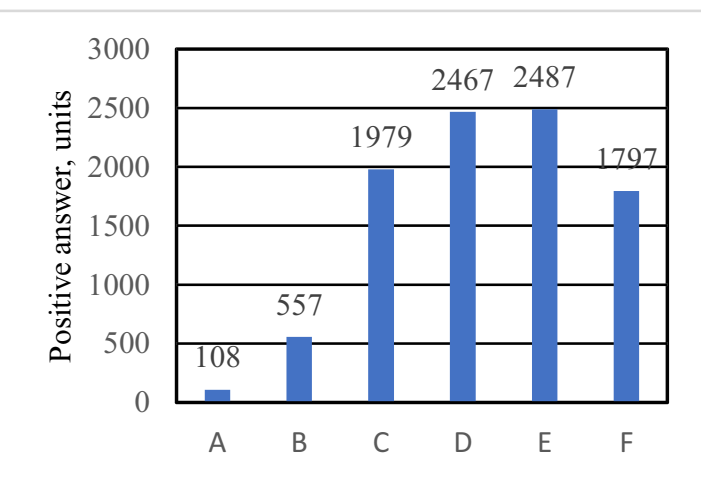

Fig. 2. Participation of students in solving environmental problems in the place of residence:

A - I always put garbage in the trash,

$\mathrm{B}$ - I participate in the development and implementation of environmental projects,

C - I do not participate in solving environmental problems,

$\mathrm{D}$ - I sort garbage,

E - I participate in one-time environmental actions,

F - I want to participate, but I don't know how to do it

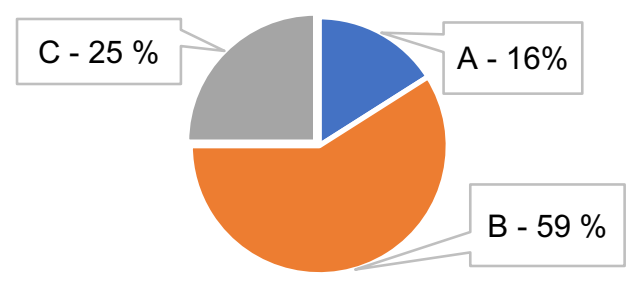

Fig. 3. The regularity of showing interest in environmental problems in social networks:

A - signed for environmental resources,

$\mathrm{B}$ - sometimes I view environmental resources,

$\mathrm{C}-$ not interested in environmental resources

Comparison of students' assessment of the environmental activity of the people around them with self-assessments of such activity (Fig. 4) indicates that students believe their environmental activity is higher than that of other people. In part this can be regarded as an overestimated conceit but on the other hand there are people with a low environmental culture who do not have a proper environmental education in the environment of students.

Students' answers to a number of other questions (Table. 1) we have divided them into three categories: positive attitude - «Yes», negative attitude - «No» and uncertain ratings «Undecided».

Table 1. Students' opinions on the possibility of influencing the environmental situation and its sustainable development

\begin{tabular}{|l|c|c|c|}
\hline \multicolumn{1}{|c|}{ Question } & Yes & No & Undecided \\
\hline Is it possible to live without harming nature? & 60 & 27 & 13 \\
\hline Is it possible to develop the economy without harming nature? & 51 & 28 & 21 \\
\hline $\begin{array}{l}\text { Does the importance of nature conservation decrease with the } \\
\text { development of scientific and technological progress? }\end{array}$ & 41 & 44 & 15 \\
\hline Does the place of residence affect the attitude to nature? & 63 & 28 & 29 \\
\hline $\begin{array}{l}\text { Is it necessary to take into account the seasonal migration of } \\
\text { animals when designing objects that are potentially dangerous } \\
\text { to nature? }\end{array}$ & 79 & 14 & 7 \\
\hline
\end{tabular}




\begin{tabular}{|l|c|c|c|}
\hline $\begin{array}{l}\text { Do you think the State is making enough efforts to solve } \\
\text { environmental problems? }\end{array}$ & 15 & 67 & 18 \\
\hline
\end{tabular}

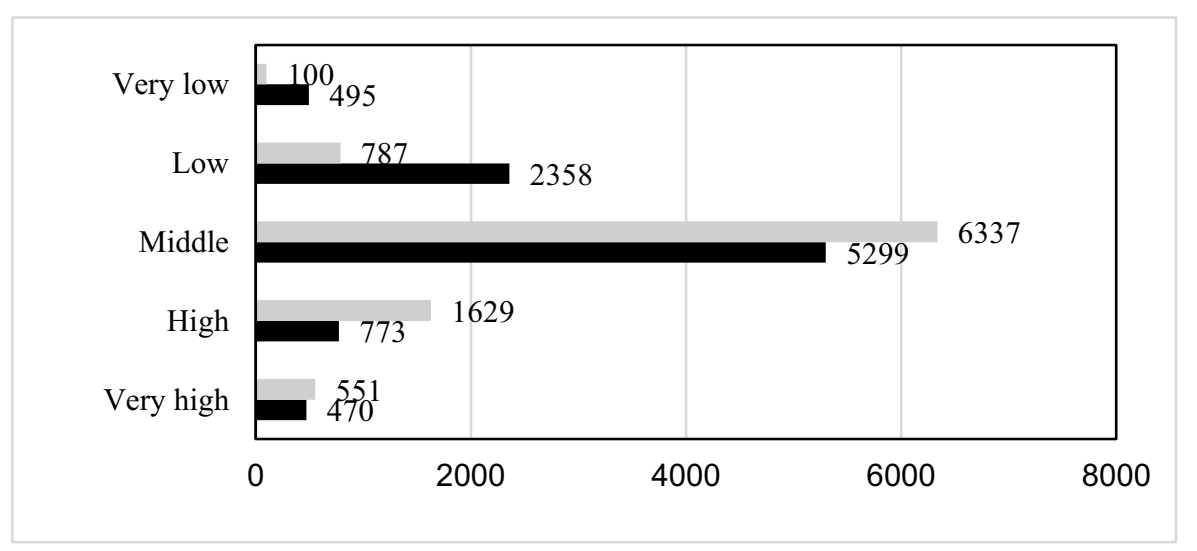

Fig. 4. The number of grades received by level of ecological culture, units: gray fill - students' assessment of the surrounding environment; black fill - students' self-assessment

The survey also established the level of awareness of students about current environmental problems in the place of residence (training) of students. Only $60-85 \%$ of students said they were familiar with local environmental issues, with the smallest number of students aware of such issues living in the capital region, and the highest number in the North Caucasus Federal District.

\section{Discussion and conclusion}

Sustainable development has now become one of the vectors of the development of civilization at the international and national levels. The improvement of professional education and the expansion of students' knowledge is an important factor in the implementation of the concept of sustainable development formed under the auspices of the United Nations. One of the main factors of updating the professional competencies of students and specialists in all areas of human activity in environmental protection is their environmental culture.

A conceptual didactic model has been developed that makes it possible to take into account the complex of human relations with the environment and the development of his personality and eco-cultural level in online and offline communication interactions.

Specific didactic models are proposed and briefly considered, according to which the process of inclusion of students in a multicultural digital educational environment provides an increase in the level of environmental culture of students. The practical implementation of pedagogical interaction on students in accordance with these models is divided into five stages of interrelated actions of teachers and students.

The experimental study made it possible to quantify the level of environmental awareness and participation of students in environmental issues.

Summarizing the responses of students received during the survey, it should be stated that there are significant reserves in improving the environmental culture of students. Therefore, in the interests of ensuring sustainable development, it is necessary to improve environmental education, regardless of the professional profile of students.

This work has been supported in part by Russian Foundation for Basic Research (RFBR), Project 19013-00322 A «Multicultural design of ecological development of personality in digital education». 


\section{References}

1. Report of the UN Conf. on environment and development. Rio de Janeiro, Brazil. 3-14 June 1992. Vol. I. A/CONF.151/26. https:/www.un.org/en/development/desa/population/migration/generalassembly/docs/globalcompact/A_CONF.151_26_Vol.I_Declaration.pdf

2. The future we want. UN Conf. on sustainable development RIO+20. Agenda item 10 . Outcome of the conference Rio de Janeiro, Brazil. 20-22 June 2012. A/CONF.216/L.1. https://sustainabledevelopment.un.org/rio20

3. Full report of the Open working group of the General Assembly on Sustainable development goals is issued as document A/68/970. (2015). http://undocs.org/A/68/970

4. Yu.M. Grishaeva, I.V. Wagner, A.V. Gagarin, I.V. Spirin, The European proceedings of social and behavioural science: 20th Conference Professional Culture of the Specialist of the Future (PCSF-2020) \& 12th Conference Communicative Strategies of Information Society (CSIS-2020), 359-371 (2020)

5. Yu.M. Grishaeva, A.V. Gagarin, Rus. J. applied research, 1, 5-8 (2020) (In Russian)

6. S.I. Makulov, O.V. Mirzabekova, Chelovek i obrazovanie (Man and Education), 4(37), 180-184 (2013) (In Russian)

7. E.A. Privalova, Bul. State univ. of humanities and social studies, 4(36), 91-95 (2019) (In Russian)

8. Yu.M. Grishaeva, S.N. Glazachev, A.V. Gagarin, I.V. Spirin, I.V. Wagner, IOP Conference Series: Material Science and Engineering. 2019 International Conference on Innovations in Automotive and Aerospace Engineering, ICI2AE, 012053 (2019)

9. V.I. Kudriavtseva, N.B. Melnik, Yu.V. Tsiplakova, O.V. Yazovskaya. Izvestia Ural federal university journal, series 3 Social and political sciences, 12(4), 46-56 (2017) (In Russian)

10. E.C. Cordero, D. Centeno, A.M. Todd. PLoS ONE, 15(2), e0206266 (2020)

11. P.F. Tunji-Olayeni, K. Kajimo-Shakantu, T.O. Ayodele, B.I. , Int. J. Construction Manag., 1-21 (2020) 